\title{
Y-STR genetic screening by high-resolution melting analysis
}

\author{
J.Q. Deng ${ }^{1 *}$, B.Q. Liu' ${ }^{2 *}$, Y. Wang ${ }^{3}$, W. Liu ${ }^{4}$, J.F. Cai ${ }^{5}$, R. Long ${ }^{1}$ and W.H. Li ${ }^{1}$ \\ ${ }^{1}$ Department of Forensic Medicine, Hainan Medical University, Haikou, China \\ ${ }^{2}$ Center of Reproductive Medicine, Affiliated Hospital of Hainan Medical University, \\ Haikou, China \\ ${ }^{3}$ Department of Bio-Chemistry and Molecular Biology, Hainan Medical University, \\ Haikou, China \\ ${ }^{4}$ Department of Medical Information Technology, Hainan Medical University, \\ Haikou, China \\ ${ }^{5}$ Department of Forensic Medicine, \\ Xiangya Medical College of Central-South University, Changsha, China \\ *These authors contributed equally to this study. \\ Corresponding author: J.Q. Deng \\ E-mail: JianqiangDeng22@163.com \\ Genet. Mol. Res. 15 (1): gmr.15017266 \\ Received July 21, 2015 \\ Accepted October 7, 2015 \\ Published February 5, 2016 \\ DOI http://dx.doi.org/10.4238/gmr.15017266
}

ABSTRACT. Currently, the widely used automated capillary electrophoresis-based short tandem repeat (STR) genotyping method for genetic screening in forensic practice is laborious, time-consuming, expensive, and technically challenging in some cases. Thus, new molecular-based strategies for conclusively identifying forensically relevant biological evidence are required. Here, we used high-resolution melting analysis (HRM) for Y-chromosome STR genotyping for forensic genetic screening. The reproducibility of the melting profile over dilution, sensitivity, discrimination power, and other factors was preliminarily studied in 10 Y-STR loci. The results showed that HRM-based approaches revealed 
more genotypes (compared to capillary electrophoresis), showed higher uniformity in replicate tests and diluted samples, and enabled successful detection of DNA at concentrations as low as $0.25 \mathrm{ng}$. For mixed samples, the melting curve profiles discriminated between mixed samples based on reference samples with high efficiency. The triplex Y-chromosome STR HRM assay was performed and provided a foundation for further studies such as a multiplex HRM assay. The HRM approach is a one-step application and the entire procedure can be completed within $2 \mathrm{~h}$ at a low cost. In conclusion, our findings demonstrate that the HRM-based Y-STR assay is a useful screening tool that can be used in forensic practice.

Key words: Genetic screening; Y chromosome; Short tandem repeats; High-resolution melting; Forensic practice

\section{INTRODUCTION}

Y-chromosome short tandem repeats (Y-STRs), also known as microsatellites and simple sequence repeats (Doutremepuich, 2012; Suehiro et al., 2013; Jiao et al., 2015), play a valuable and important role in forensic molecular biology. These sequences are comprehensively used in forensics to examine sperm from a vaginal swab of a raped or murdered female victim and to exclude a falsely convicted male. Thus, Y-STRs in combination with autosomal STRs can be employed preferentially in sexual assault cases to reconstruct paternal relationships and provide information regarding the ethnic origin of a male DNA donor (Keyser-Tracqui and Ludes, 2003; Roewer, 2009; Andersen et al., 2015).

Traditionally, Y-STR genotyping protocols employ locus-specific polymerase chain reaction (PCR) to amplify target DNA fragments, which are separated using laborious polyacrylamide gels involving radioactive detection methods, carcinogenic DNA stains, or silver staining. Over the last decade, automated capillary electrophoresis (CE) systems with fluorescence-labeled primers have been widely used in STR genotyping. Although CE significantly improved the throughput and automation, the procedure is costly and requires laborious post-PCR handling (Ziętkiewicz et al., 2012; Thompson et al., 2012). Additionally, electrophoresis-based methods only differentiate genotypes of length polymorphisms, while nucleotide variations such as single nucleotide polymorphisms (SNPs) in the flanking sequences of a repeat motif cannot be detected. Therefore, more potentials of the marker system have been restrained by the approaches to analyze the markers (Butler et al., 2004; Butler, 2007; Pascali et al., 2012). Thus, there is an urgent for new STR genotyping approaches.

Recently, high-resolution melting analysis (HRM), which utilizes DNA intercalating dye to measure fluorescence changes during double-strand DNA melting, has been shown to be a powerful method for analyzing genetic variations including SNPs, insertions or deletions, and DNA methylation. The HRM PCR is a closed-tube and post-PCR method that enables rapid analysis of genetic sequences (Wittwer, 2009; Vossen et al., 2009; Er and Chang, 2012; Wojdacz, 2012). However, few genotypes and markers have been tested and it is unclear whether HRM can be used as an alternative to electrophoresis-based methods for microsatellite detection. In this report, we conducted a Y-STR genotyping study using HRM and discuss its potential use in common forensic practices. 


\section{MATERIAL AND METHODS}

\section{DNA isolation}

Blood samples were obtained from 30 unrelated, autochthonous healthy male individuals after obtaining informed consent. Genomic DNA was isolated using 3 methods: Blood MiNi Kit (CW Biotech Inc., Beijing, China), Genomic DNA Isolation Kit (Foregene Co., Ltd., Chengdu, China), and a method previously reported by Walsh et al. (1991), using the chelex-100 DNA extraction procedure. All extracted DNA was quantified spectrophotometrically.

\section{Y-STR genotyping}

Ten loci (DYS391, DYS449, DYS447, DYS19, DYS393, DYS444, DYS390, DYS392, DYS522, DYS389 I/II) from each DNA sample were genotyped both by automated CE and HRM (Tables 1 and 2).

\section{Automated CE analysis}

\section{PCR}

PCR amplification was performed using approximately 1-3 ng genomic DNA in a total reaction volume of $10.0 \mu \mathrm{L}$ consisting $4.0 \mu \mathrm{L}$ reaction mix, $1.0 \mu \mathrm{L}$ Hot Start C-Taq polymerase, and $2.0 \mu \mathrm{L}$ Y 24 primer set. Amplification was carried out in a 9600 Hema TE Thermo Cycler (Hema Medical Instrument Co., Ltd., China) (CW Biosystems, invitrogen, A11312) in 3 steps, according to the manufacturer protocol (AGCU Y24 STR kit, AGCU Life Co., China). Briefly, the first with 10 cycles were conducted under the following conditions: $94^{\circ} \mathrm{C}$ for $1 \mathrm{~min}, 62^{\circ} \mathrm{C}$ for $1 \mathrm{~min}, 72^{\circ} \mathrm{C}$ for $1 \mathrm{~min}$; then 20 cycles under the following conditions: $90^{\circ} \mathrm{C}$ for $1 \mathrm{~min}, 58^{\circ} \mathrm{C}$ for $1 \mathrm{~min}, 72^{\circ} \mathrm{C}$ for $1 \mathrm{~min}$; extension at $60^{\circ} \mathrm{C}$ for $60 \mathrm{~min}$.

\section{Typing}

After PCR, 1.0 $\mu \mathrm{L}$ DNA was combined with $12 \mu \mathrm{L}$ formamide and $0.5 \mu \mathrm{L}$ size standard (GeneScan 500 LIZ; Thermo Fisher Scientific, Waltham, MA, USA). Electrophoresis, detection of PCR products, and genotyping were carried out on the ABI PRISM 3130 Avant DNA Analyzer (Applied Biosystems Division/Perkin-Elmer, Foster City, CA, USA) using ABI PRISM 3130 data collection, GeneScan analysis 3.1, and Genotyper softwares (Applied Biosystems).

\section{HRM analysis}

Some PCR primers were designed either by using the STRbase DNA database (http:// www.cstl.nist.gov/strbase) or on the basis of previously published literature (Tang et al., 2003; Butler et al., 2006), which was followed by synthesis by Sigma Oligo (Sigma-Aldrich, St. Louis, MO, USA). The Type-it HRM PCR Kit was purchased from Qiagen (Hilden, Germany). Each PCR mix was prepared using approximately 1-3 ng genomic DNA in a total reaction volume of $10.0 \mu \mathrm{L}$ consisting of $5.0 \mu \mathrm{L} 2$ X HRM PCR Master Mix (containing the fluorescent dye EvaGreen), and 0.7 $\mu \mathrm{L} 10 \mu \mathrm{M}$ primer mix set (following the recommendations from the manufacturer). PCR cycling and HRM analysis were carried out in one step using a Rotor-Gene Q thermal cycler (Qiagen), which 
has a thermal uniformity of $\pm 0.01^{\circ} \mathrm{C}$ and resolution $\pm 0.02^{\circ} \mathrm{C}$. The thermal program consisted of an initial denaturation step of $94^{\circ} \mathrm{C}$ for $10 \mathrm{~min}$ followed by 32 cycles of $94^{\circ} \mathrm{C}$ for $30 \mathrm{~s}$, annealing for $30 \mathrm{~s}$, and $72^{\circ} \mathrm{C}$ for $45 \mathrm{~s}$. After $32 \mathrm{PCR}$ cycles, melting curve data were generated by increasing the temperature from $60^{\circ}$ to $95^{\circ} \mathrm{C}$ at $0.1^{\circ} \mathrm{C} / \mathrm{s}$ while recording fluorescence. HRM curve analysis was performed using the Rotor-Gene 2.3.1 software, and the HRM algorithm was provided.

The Male Genomic DNA Standard 9948 at a concentration of $0.1 \mathrm{ng} / \mu \mathrm{L}$, provided with the QIAGEN kit, was used to investigate the sensitivity of HRM analysis at different initial DNA concentrations using a serial 2-fold dilution method, including $0.1,0.05,0.025,0.0125$, and $0.00625 \mathrm{ng} / \mu \mathrm{L}$.

\section{DNA sequencing}

Samples containing or expressing different genotypes, detected by CE and HRM, were sequenced by SinoGenoMax Co., Ltd. (Beijing, China).

\section{RESULTS}

Ten Y-STRs (all with a single-copy locus) used in the forensic field were chosen for the initial analysis (Table 1). For each locus, primers were chosen to generate single-gene sequences and PCR products less than 400 bp (Doutremepuich, 2012). Each STR was initially tested using several DNA samples to evaluate whether the primers worked by performing HRM melting analysis in a Rotor-Gene Q. During the PCR procedure, the target sequence was amplified to a high-copy number in the presence of the double-stranded DNA-binding fluorescent dye EvaGreen. When melting curve analysis is performed using the EvaGreen intercalating dye, the double-stranded DNA is fluorescent and can be measured continuously until a temperature near the melting point $(\mathrm{Tm})$ is reached. At the $\mathrm{Tm}$, fluorescence decreases rapidly because of strand dissociation (dye elimination) and then plateaus at a residual fluorescent value (Figure 1). This is a result of the EvaGreen dye properties whose fluorescence decreases several hundredfold when it is not intercalated into double-stranded DNA (Liu and Wu, 2015). Since strand dissociation can begin internally both in lower melting domains and mismatched regions, STR amplicons differ by integral numbers of $4 \mathrm{bp}$, allowing for repeats to be discriminated from one another (Figure 1).

Table 1. General information of 10 Y-STRs.

\begin{tabular}{|c|c|c|c|c|}
\hline Locus & Forward primer (5'-3') & Reverse primer (5'-3') & Repeat structure & $\begin{array}{l}\text { Product } \\
\text { size }\end{array}$ \\
\hline DYS391 & CTATTCATTCAATCATACACCCA & GATTCTTTGTGGTGGGTCTG & {$[\text { TCTA })_{n}$} & 268 \\
\hline DYS449 & AAAAGGCATATGTCAAAATCT & TAGGTTGGACAACAAGAGTAA & {$[\text { TTTC }]_{m} N_{50}[\text { TTTC }]_{n}$} & 339 \\
\hline DYS447 & GGTCACAGCATGGCTTGGTT & GGGCTTGCTTTGCGTTATCTCT & $\begin{array}{c}{[\text { TAATA }]_{n}[\text { TAAAA }]_{1}[\text { TAATA }]_{p}[\text { TAAAA }]_{1}[\text { TA }} \\
\text { ATA }]_{q}\end{array}$ & 202 \\
\hline DYS19 & CTACTGAGTTTCTGTTATAGT & ATGGCCATGTAGTGAGGACA & {$[\mathrm{TAGA}]_{3}$ tagg $[\mathrm{TAGA}]_{7}$} & 143 \\
\hline DYS393 & GTGGTCTTCTACTTGTGTCAATAC & AACTCAAGTCCAAAAAATGAGG & {$[A G A T]_{n}$} & 107 \\
\hline DYS444 & TTTCTСТСТTCCСACTTTAACCAG & CTCACGTTGTTCAAGGGTCA & {$[\text { TATAG }]_{n}$} & 304 \\
\hline DYS390 & TATATTTTACACATTTTTTGGGCC & TGACAGTAAAATGAACACATTGC & {$[T C T G]_{n}[T C T A]_{m}[T C T G]_{p}[T C T A]_{q}$} & 188 \\
\hline DYS392 & TCATTAATCTAGCTTTTAAAAACAA & AGACCCAGTTGATGCAATGT & {$[\mathrm{TAT}]_{\mathrm{n}}$} & 234 \\
\hline DYS522 & CСTTTGAAATCATTCATAATGC & TCATAAACAGAGGGTTCTGG & {$[\mathrm{GATA}]_{\mathrm{n}}$} & 340 \\
\hline DYS389 I/II & ССААСТСТСАТСТGТАТTАТСТАТG & $\begin{array}{l}\text { GTTATCCCTGAGTAGTAGAAGAA } \\
\text { TG }\end{array}$ & $\begin{array}{c}\text { I: }[\text { TCTG }]_{q}[\text { TCTA }]_{\mathrm{r}} \\
\text { II: }[\text { TCTG }]_{n}[\text { TCTA }]_{p}[\text { TCTG }]_{q}[\text { TCTA }]_{r}\end{array}$ & $\begin{array}{l}\text { I: } 235 \\
\text { II: } 255\end{array}$ \\
\hline
\end{tabular}



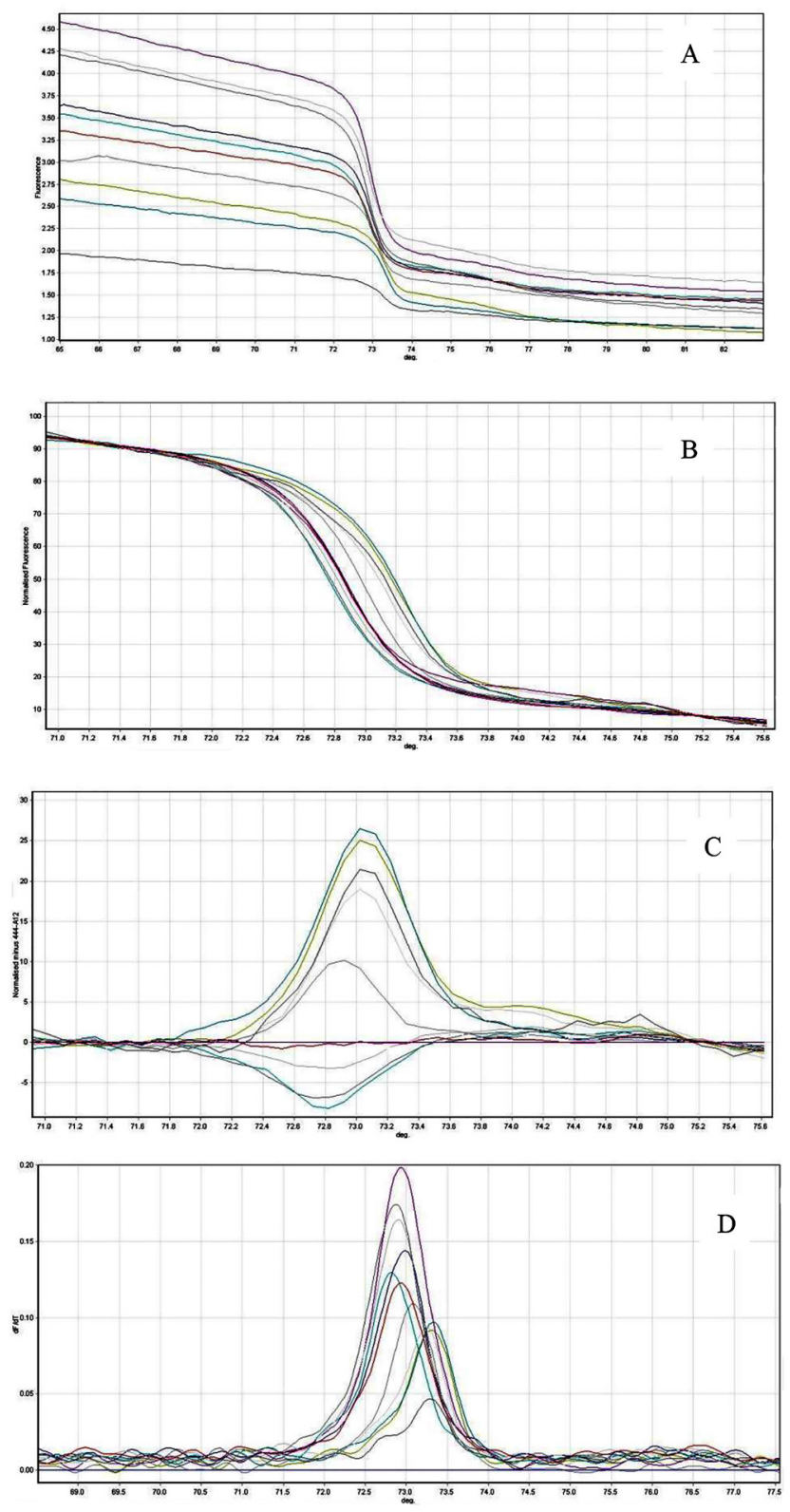

Figure 1. Melt curve profiles and difference curves of 10 genotypes of DYS444. Curves in different colors indicate different samples; same colored curve in the 4 profiles of Figure 1 indicate the same sample (Figure $1 \mathrm{~A}$ was chosen for the color presented for genotype, i.e., genotypes of $33,32,30,28,34,25,27,29,26$, and 31 are shown from up to down in turns). A. Raw melt curve data. B. Normalized graph. C. Difference graph: the DYS449 genotype 25 was selected using the software as the reference to which other samples were compared (shown as the baseline across the temperature range). D. Melt curve analysis. Difference curves to easily distinguish between genotypes. Melt curves were assigned to 10 different groups by the software. 
The Rotor-Gene 2.3.1 software can produce 4 types of profiles: raw analysis curve, normalized graph, difference graph, and melt curve analysis. Raw melt curve data revealed individual variation between reaction samples because of differences in starting template concentrations, in the optical detection efficiency of fluorescence between samples, slight positional temperature differences between wells, and solution components such as the solvent used and the salt/solute concentration (Figure 1A). Following PCR, the genotype-calling software in Rotor-Gene Q allows users to normalize well-to-well differences in both fluorescence intensity and temperature (Figure 1B), allowing melting curves to be accurately compared between different PCRs. This aids in the grouping similar genotypes. Difference curves (Figure 1C and D) help to visually distinguish different genotypes from one another by setting one genotype as the reference profile or baseline for comparison. The extent to which other melting curves differ from this reference is then plotted as a positive or negative displacement or change in fluorescence ( $y$-axis) as a function of temperature (x-axis) (Figure 1D). Our initial studies revealed divergence in the amplification efficiency of some STRs (data not shown). To address this, several amplification parameters were adjusted, including annealing temperature, annealing and extension times, primer concentration, and amplification cycle numbers. Among these parameters, we found that the annealing temperature was the most important factor affecting the HRM results (Figure 2). Other factors that gave the best amplification included increasing the annealing and extension times and raising the primer concentrations. These factors were implemented in all subsequent experiments. The influence of PCR volumes $(10,15,20$, and $25 \mu \mathrm{L})$ was also investigated and similar results were obtained (data not shown); thus, we choose $10 \mu \mathrm{L}$ as the unified PCR volume. Other conditions were also unified according to the above conclusions, including the initial denaturation step at $94^{\circ} \mathrm{C}$ for $10 \mathrm{~min}$ followed by 32 cycles at $94^{\circ} \mathrm{C}$ for $30 \mathrm{~s}$, annealing (each locus with its proper anneal temperature) for $30 \mathrm{~s}$, and $72^{\circ} \mathrm{C}$ for $45 \mathrm{~s}$, then $72^{\circ} \mathrm{C}$ for $10 \mathrm{~min}$ for the final extension (Table 2).

The assay was then tested for reproducibility, uniformity for a known genotype, and melting profile consistency in various dilutions. Each STR primer set was tested against 40 DNA samples, for which the genotypes had been determined by CE analysis. The HRM results were very consistent and stable. Table 2 summarizes the results of these tests, showing the approximate numbers of genotypes that could be resolved by differences in melting profiles in the studied samples. Overall, more genotypes were identified by HRM than by CE. We also found that although the HRM patterns of Y-STRs with a single amplicon showed a unique peak for most loci (Figures 1 and 2), we sometimes observed 2 peaks (Figure 3); the reason for this requires further investigation.

The results also showed that samples with different genotypes produced different melting profiles, which can differentiate the samples. Melting profiles were essentially unchanged after the tubes had remained for 1 month at $4^{\circ} \mathrm{C}$ in all studied samples and for all loci (Figure 4). Table 3 shows Tm peaks at some loci for 5 individuals over 30 days (Table 3). Percent standard deviations (standard deviation divided by the mean) were all greater than $1 \%$ (most were $<0.1 \%$ ), the results were the same for each sample even after testing numerous times by HRM analysis (Figure 5).

No correlation was observed between the number of distinguishable patterns and STR length or amplicon length, and more genotypes were found using HRM analysis than CE analysis. Table 4 shows the grouping of genotypes by HRM patterns and which genotypes could not be distinguished by visual inspection. However, not all genotypes must be distinguished in order for the screening assay to be effective. In some cases, HRM can be used to distinguish between individuals with the same STR genotypes. Figure 6 shows individuals expressing the same genotype (such as allele 12 of DYS393) but with different melting profiles. These differences were reproducible and were likely 
observed because some alleles of the same length (thus, have the same allele designation based on fragment analysis) have different sequences and thus different melting characteristics. The Short Tandem Repeat DNA DataBase lists a number of known sequence differences for some STR loci, but no sequence differences are listed for DYS393. This was observed in nearly all of our studied Y-STRs.
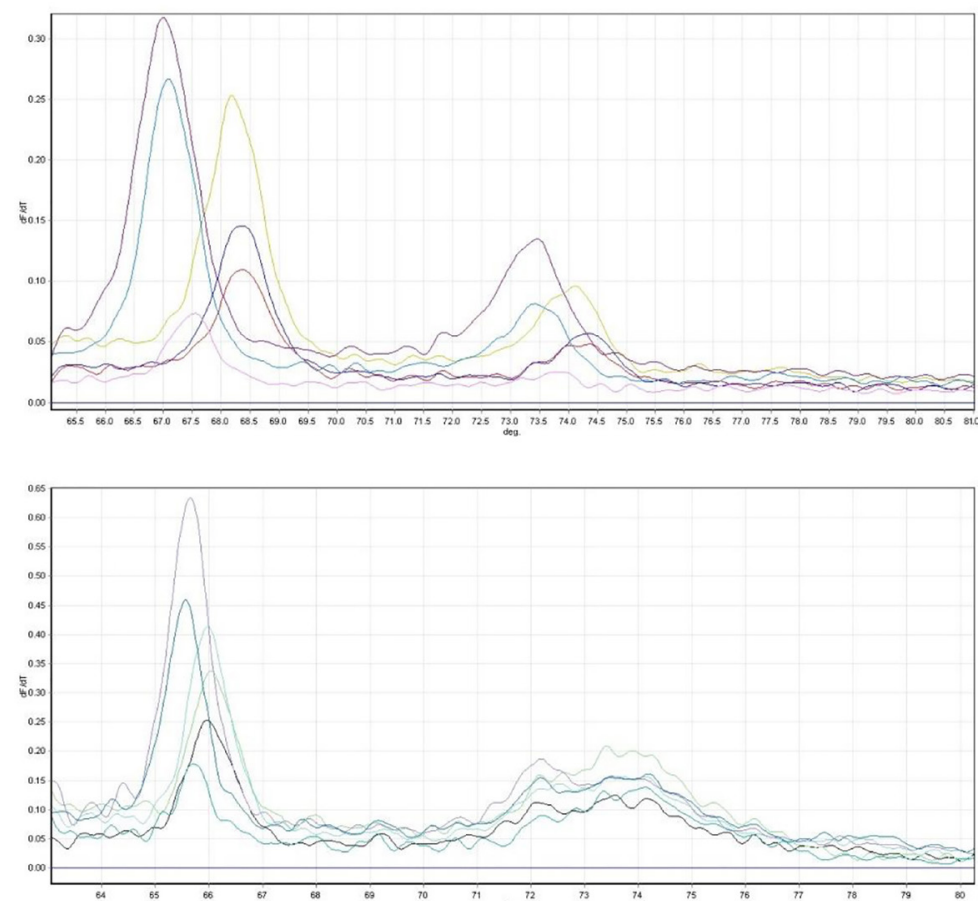

Figure 2. Inappropriate annealing temperature resulting in the appearance of an obvious pseudo-peak in DYS447. Top and bottom parts of the figure show the results for 6 samples with different annealing temperatures; the top part of the figure was under $53^{\circ} \mathrm{C}$, while the bottom part of the figure was under $54^{\circ} \mathrm{C}$, while other reactions and amplification conditions were the same.

Table 2. Approximate number of genotypes that could be easily differentiated for the 10 Y-STRs studied.

\begin{tabular}{|c|c|c|c|c|}
\hline Locus & $\begin{array}{l}\text { Annealing } \\
\text { temperature }\end{array}$ & $\begin{array}{c}\text { Allele melting } \\
\text { temperature range }\end{array}$ & $\begin{array}{l}\text { Number of genotypes present in } \\
\text { samples }\end{array}$ & $\begin{array}{l}\text { Number of distinct } \\
\text { melting patterns }\end{array}$ \\
\hline DYS391 & $59.7^{\circ} \mathrm{C}$ & $80-84^{\circ} \mathrm{C}$ & 2 & 5 \\
\hline DYS449 & $54^{\circ} \mathrm{C}$ & $75-77^{\circ} \mathrm{C}$ & 10 & 11 \\
\hline DYS447 & $54^{\circ} \mathrm{C}$ & $64-68^{\circ} \mathrm{C}$ & 6 & 9 \\
\hline DYS19 & $54^{\circ} \mathrm{C}$ & $75-85^{\circ} \mathrm{C}$ & 4 & 5 \\
\hline DYS522 & $57.3^{\circ} \mathrm{C}$ & $75-81^{\circ} \mathrm{C}$ & 5 & 6 \\
\hline DYS393 & $55.4^{\circ} \mathrm{C}$ & $71-74^{\circ} \mathrm{C}$ & 3 & 5 \\
\hline DYS444 & $57.3^{\circ} \mathrm{C}$ & $71-75^{\circ} \mathrm{C}$ & 5 & 8 \\
\hline DYS390 & $54.9^{\circ} \mathrm{C}$ & $74-78^{\circ} \mathrm{C}$ & 4 & 6 \\
\hline DYS392 & $57.5^{\circ} \mathrm{C}$ & $70-78^{\circ} \mathrm{C}$ & 2 & 7 \\
\hline DYS389 I/II & $54.9^{\circ} \mathrm{C}$ & $74-83^{\circ} \mathrm{C}$ & I: $2 ;$ II: 4. & 9 \\
\hline
\end{tabular}




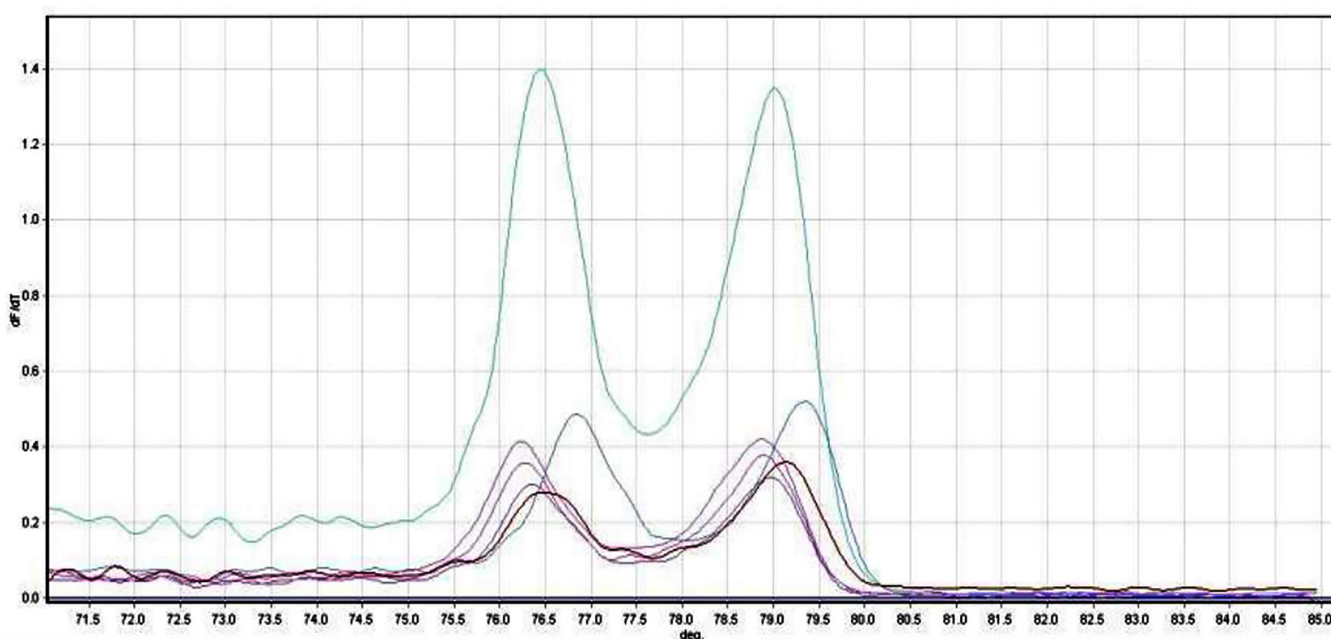

Figure 3. HRM analysis results showed 2 peaks in all detected samples of DYS522.


Figure 4. Results of same HRM-PCR products detected in DYS393 immediately and 30 days after. Top part of figure shows the HRM profiles of immediate detection, while bottom part of figure shows the HRM profiles of detection 30 days later. 
Table 3. Reproducibility of melting temperatures of HRM peaks for 5 individuals run 3 times.

\begin{tabular}{l|c|c|c|c|c|c|c}
\hline Sample & Melting peak & Instant & Day 15 & Day 30 & Average & SD & \%SD \\
\hline DYS522 & & & & & & & \\
\hline Individual 1 & 2 & 78.91 & 78.43 & 77.97 & 78.44 & 0.38 & 0.49 \\
\hline Individual 2 & 2 & 77.03 & 76.34 & 75.47 & 76.28 & 0.64 & 0.84 \\
\hline Individual 3 & 2 & 77.78 & 76.67 & 76.32 & 76.92 & 0.62 & 0.81 \\
\hline Individual 4 & 2 & 77.62 & 77.22 & 76.8 & 77.21 & 0.33 & 0.43 \\
\hline Individual 5 & 2 & 77.88 & 77.38 & 76.92 & 77.39 & 0.39 & 0.51 \\
\hline DYS447 & & & & & & & \\
\hline Individual 1 & 1 & 65.96 & 65.43 & 65.00 & 65.70 & 0.41 & 0.62 \\
\hline Individual 2 & 1 & 66.38 & 66.56 & 66.93 & 66.47 & 0.24 & 0.36 \\
\hline Individual 3 & 1 & 66.83 & 66.14 & 65.93 & 66.30 & 0.37 & 0.58 \\
\hline Individual 4 & 1 & 65.77 & 65.33 & 64.66 & 65.55 & 0.48 & 0.73 \\
\hline Individual 5 & 1 & 65.74 & 65.23 & 65.27 & 65.49 & 0.24 & 0.36 \\
\hline DYS391 & & & & & & & \\
\hline Individual 1 & 1 & 82.38 & 81.98 & 81.78 & 82.18 & 0.26 & 0.31 \\
\hline Individual 2 & 1 & 82.64 & 82.43 & 82.21 & 82.54 & 0.18 & 0.22 \\
\hline Individual 3 & 1 & 81.96 & 81.25 & 80.94 & 81.60 & 0.44 & 0.54 \\
\hline Individual 4 & 1 & 82.71 & 81.98 & 81.72 & 82.34 & 0.43 & 0.52 \\
\hline Individual 5 & 1 & 82.84 & 82.63 & 82.11 & 82.74 & 0.32 & 0.39 \\
\hline
\end{tabular}

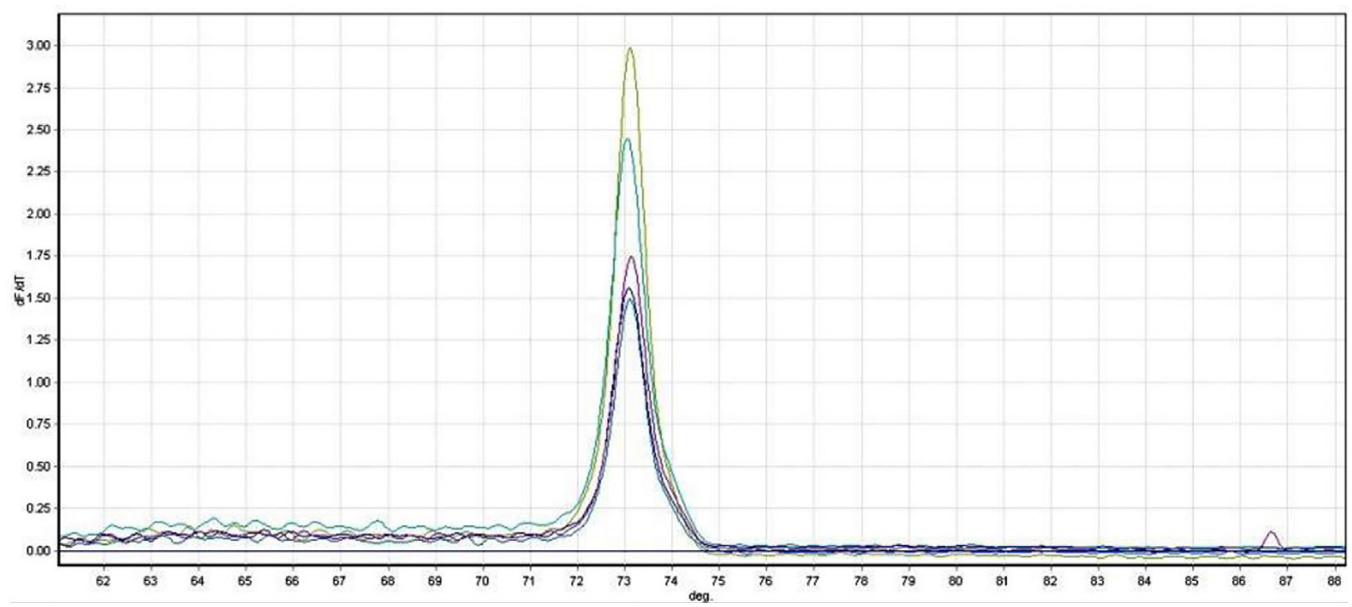

Figure 5. Results of duplicate detection of one individual of DYS444 5 times.

DNA sequencing was subsequently performed to determine whether amplicon sequence variations explained why some samples with the same genotype produce different HRM patterns. For this, DNA sequencing was performed on 5 pairs of samples that had the same DYS449 genotype, as determined by CE, but showed different HRM patterns. Some DNA sequence variations were observed in the sequence flanking the DYS449 motif in one sample (Figure 7), illustrating that single-base differences may affect the HRM pattern for STRs. Sequencing of another sample also showed a clear difference between the 2 samples, with different HRM patterns because of alignment differences for the motif, such as (TTTC) ${ }_{14} \mathrm{~N}_{50}(\text { TTTC) })_{11}$ to (TTTC) ${ }_{13} \mathrm{~N}_{50}\left(\right.$ TTTC) ${ }_{12}$, although their genotypes were the same (i.e., genotype 25). 
Table 4. Common genotypes in each group that could (different groups) and could not (same groups) be distinguished.

\begin{tabular}{c|c|c|c}
\hline Loci & $\begin{array}{c}\text { Alleles } \\
\text { detected }\end{array}$ & $\begin{array}{c}\text { Alleles differing } \\
\text { by HRM }\end{array}$ & $\begin{array}{c}\text { Numbers of new genotypes } \\
\text { found by HRM }\end{array}$ \\
\hline DYS391 & 10,11 & 10,11 & 3 \\
\hline DYS449 & $25,26,27,28,29,30,31,32,33,34$ & $25,27,28,30$ & 1 \\
\hline DYS447 & $23,24,25,26,27,28$ & $23,25,27,28$ & 3 \\
\hline DYS19 & $14,14.3,15,16$ & $14,15,16$ & 1 \\
\hline DYS522 & $9,10,11,12,13$ & $10,11,12$, & 2 \\
\hline DYS393 & $12,13,14$ & $12,13,14$ & 3 \\
\hline DYS444 & $10,11,12,13,14$ & $10,11,12,13,14$ & 2 \\
\hline DYS390 & $23,24,25,26$ & $23,24,25$ & 5 \\
\hline DYS392 & 13,14 & 13,14 & - \\
\hline DYS389 & $1: 12,13 ;$ & - & \\
\hline
\end{tabular}

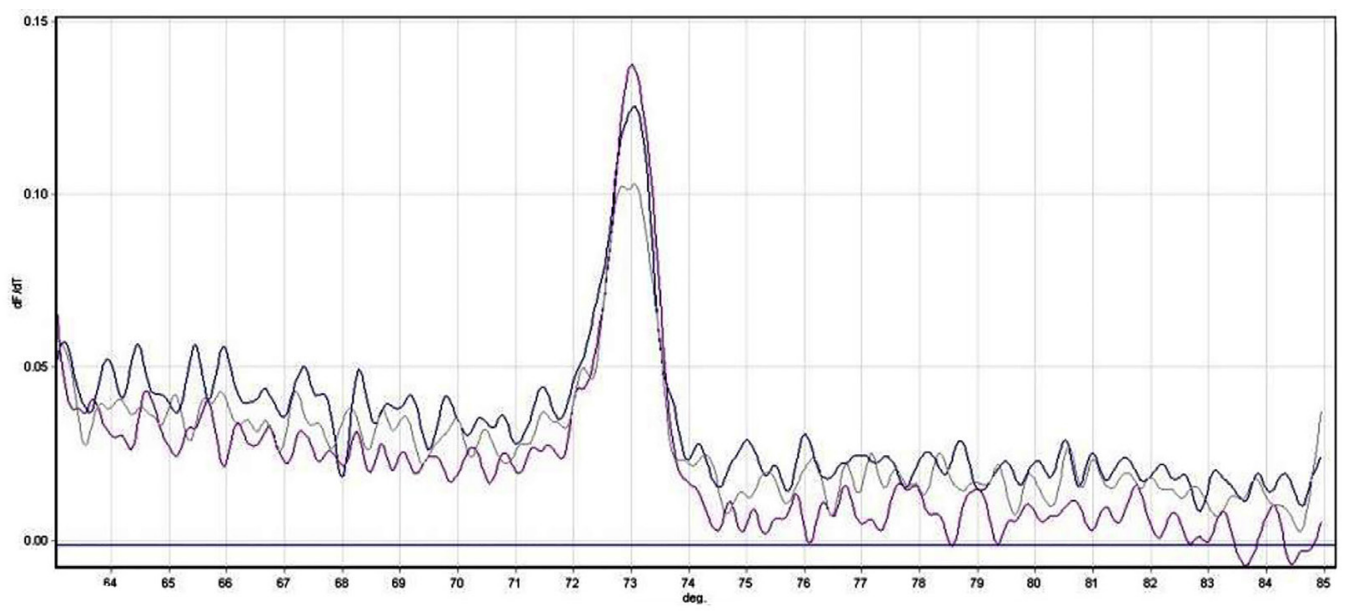

Figure 6. No correlation between number of distinguishable patterns and STR length or amplicon length was found by HRM analysis of DYS393 in the same samples; samples with the genotypes 12, 13, and 14 showed the same melting curves.

We also found that similarly to samples genotyped by CE, DNA degradation (DNase I-treated) did not affect the HRM assay (data not shown). DNA samples obtained using different DNA extraction methods were also studied, and no difference was observed in the melting profiles between DNA isolated using the two different methods (data not shown).

Next, we evaluated the ability of HRM for STR screening and found that although it was difficult to discriminate the samples based on HRM profiles by one locus for some samples, the Rotor-Gene $Q$ allowed the user to test fewer than 36 samples for one test. Thus, loci with different Tms can be detected in one test, making it convenient to add additional loci for discrimination. A blind experiment involved 3 separate amplifications. Each run was tested for DYS391, DYS392, and DYS393, which were selected because they had no overlapping Tms for HRM. They were easy to show in one profile, and for 30 unique samples. For all 30 samples, only 2 melting profiles (the 3 loci were combined as a whole for all samples) matching another profile. When these data 
were evaluated against the actual genotypes, the 2 samples were found to have exactly the same genotypes for the 3 loci. The tests demonstrated the excellent ability of this method to distinguish individuals in a much more powerful assay for HRM screening using different locus combinations (Figure 8).
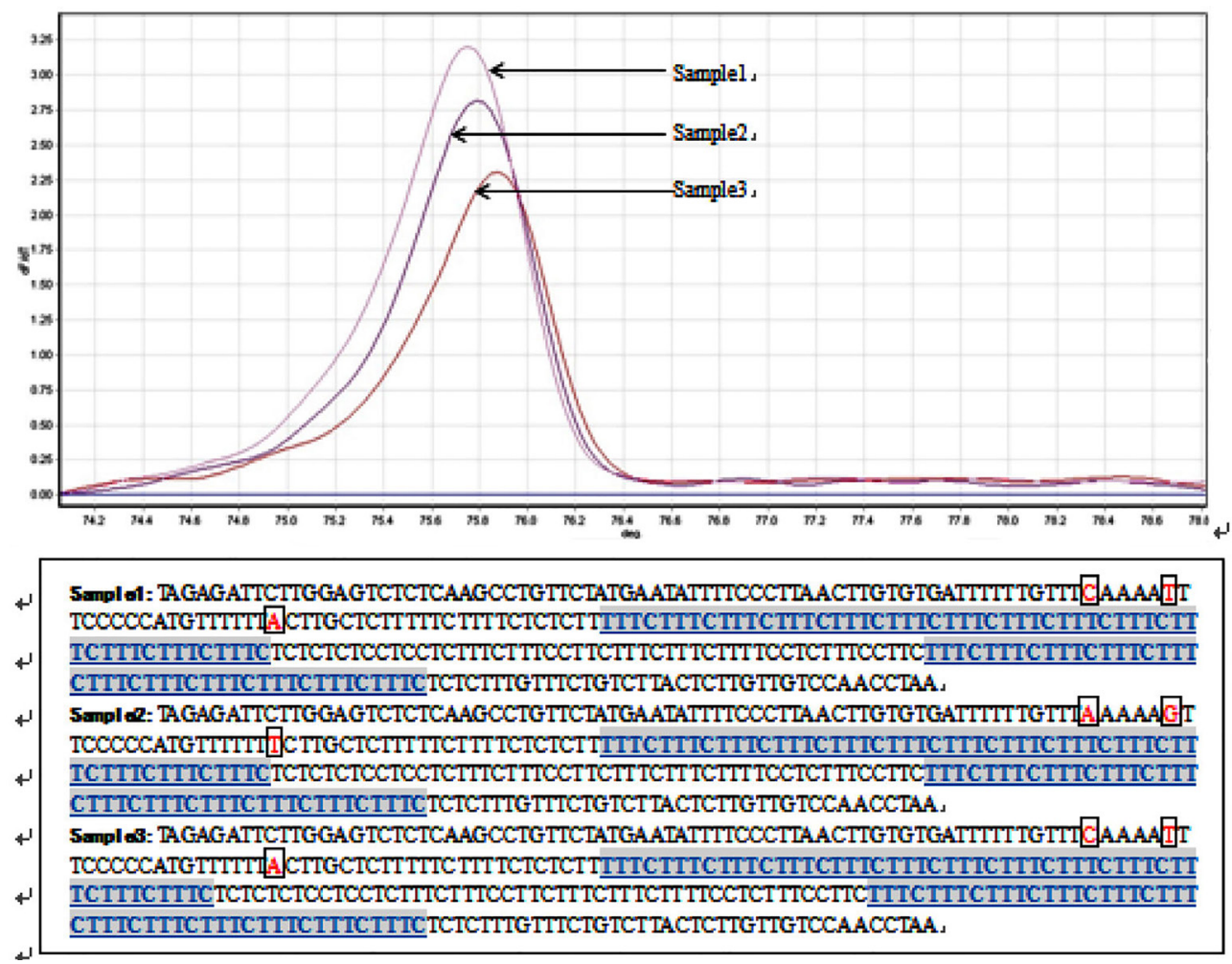

Figure 7. Three samples with the same genotype detected by CE with different HRM profiles of DYA449. The top shows that 3 samples with same genotype 25 produced different HRM profiles. The bottom shows the sequencing results of the 3 samples: referring to the sequence of sample 1, flanking sequence difference was found in sample 2, i.e., C and T were changed to $A$ and $G$, respectively. Alignment difference was found in sample 3, i.e., (TTTC $)_{14} N_{50}(\text { TTTC })_{11}$ to $(\text { TTTC })_{13} \mathrm{~N}_{50}(\text { TTTC })_{12}$.

In order to simplify sample discrimination, we used a multiplex assay so that different loci could be displayed simultaneously for a sample and 2 samples could be easily compared. We identified some loci with the same annealing temperature but with different and non-overlapping Tms for HRM (for example: DYS447, DYS449, and DYS19); these loci were chosen to generate a triplex assay. The experiment was performed in this manner so that in a single amplification, all 3 loci of the tested samples could be compared. The results for the tests were promising (Figure 9). However, when we tested the 3 loci in one mixture, only DYS449 was successfully detected, indicating that the multiplex STR HRM assay in one tube requires further development. We also performed an HRM assay for the multi-STR products, which were prepared for CE analysis but only showed noise signals, making it impossible to conduct genotyping by HRM (Figure 9). 

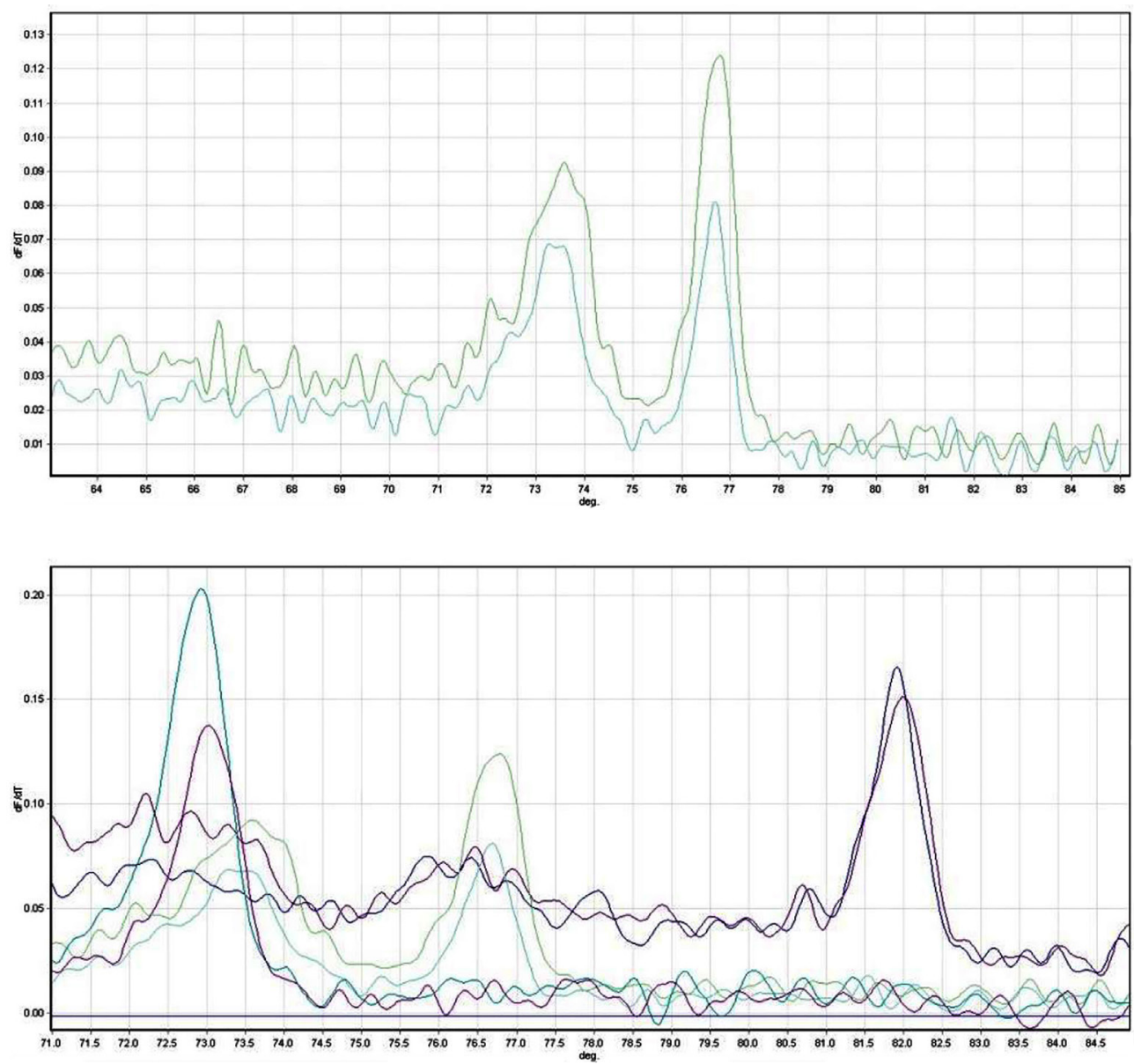

Figure 8. Two samples were discriminated by HRM assay. The top shows 2 samples that could not be discriminated by HRM profiles of DYS392. The bottom shows that the 2 samples were discriminated by adding more loci, i.e., DYS391 and DYS393.

For the mixture experiments, 2 mixtures composed of DNA from separate donors with different DYS449 genotypes were examined by HRM analysis over a range of mixture ratios. The PCRs contained $1 \mathrm{ng}$ DNA per reaction and were separated according to the following mixture ratios: $5 / 0,4 / 1,3 / 2,3 / 3,2 / 3,1 / 4$, and $0 / 5$. Using the HMR approach, individual DNA samples were differentiated based on differences observed in the melting curves. The profiles of the mixtures were often not a combination of the 2 melting profiles of the individual DNAs; however, unique melting curves were produced for many of the samples, which were easily discriminated from the original samples (Figure 10).

Figure 11 shows the sensitivity of the HRM assay for DYS393, and the amounts of original DNA were $0.1,0.05,0.025,0.0125,0.00625$ ng per reaction. 

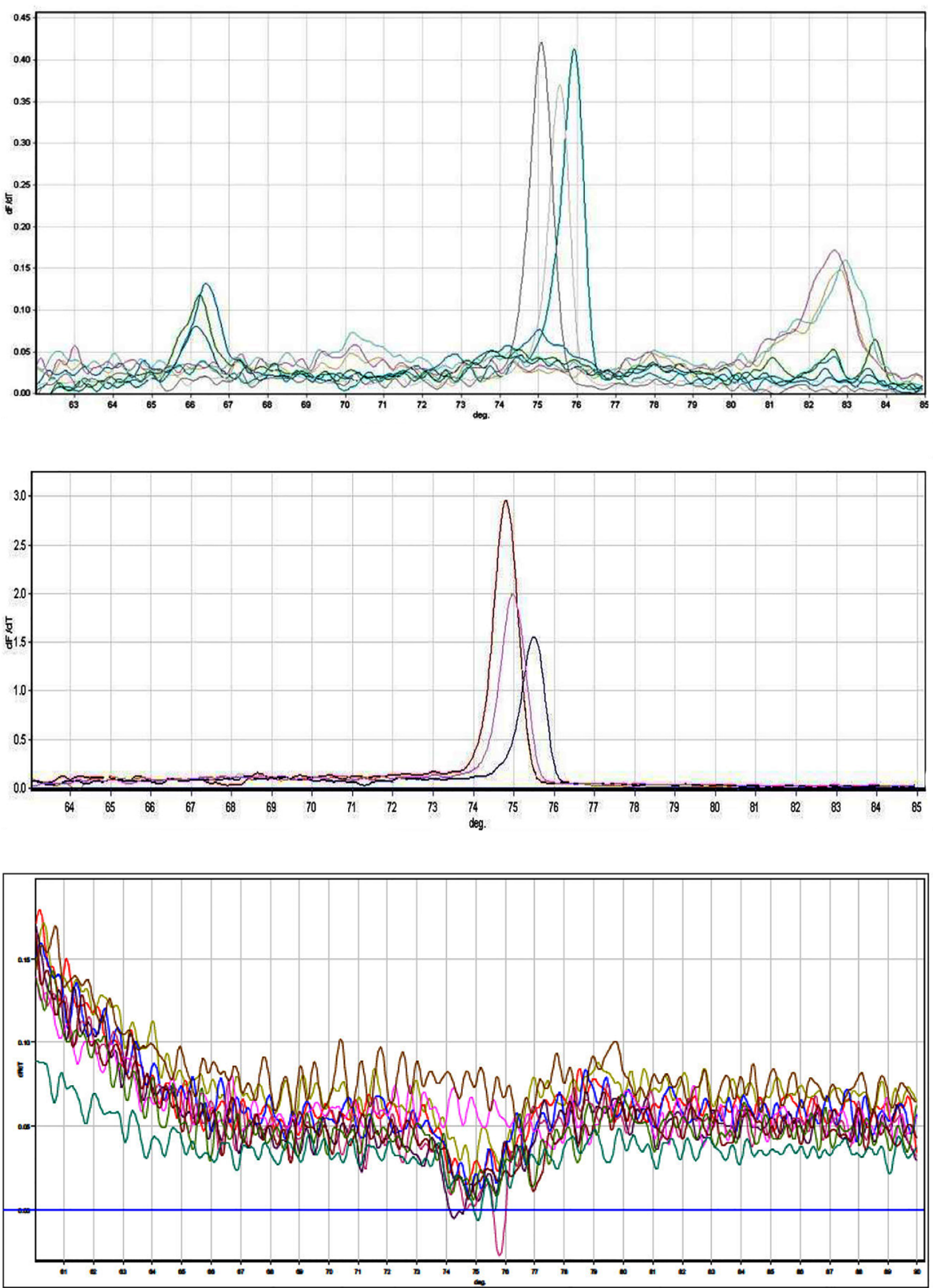

Figure 9. Triplex STR HRM assay. The top part of the figure shows samples tested with separate tubes for different loci, but amplified and detected by HRM together: from left to right are loci DYS447, DYS449, and DYS19. The 3 samples were easily identified. The middle of the figure shows samples tested in one tube for different loci, in which only DYS449 was detected. The bottom part of the figure shows the HRM assay result of the multi-STR products prepared for CE analysis. 

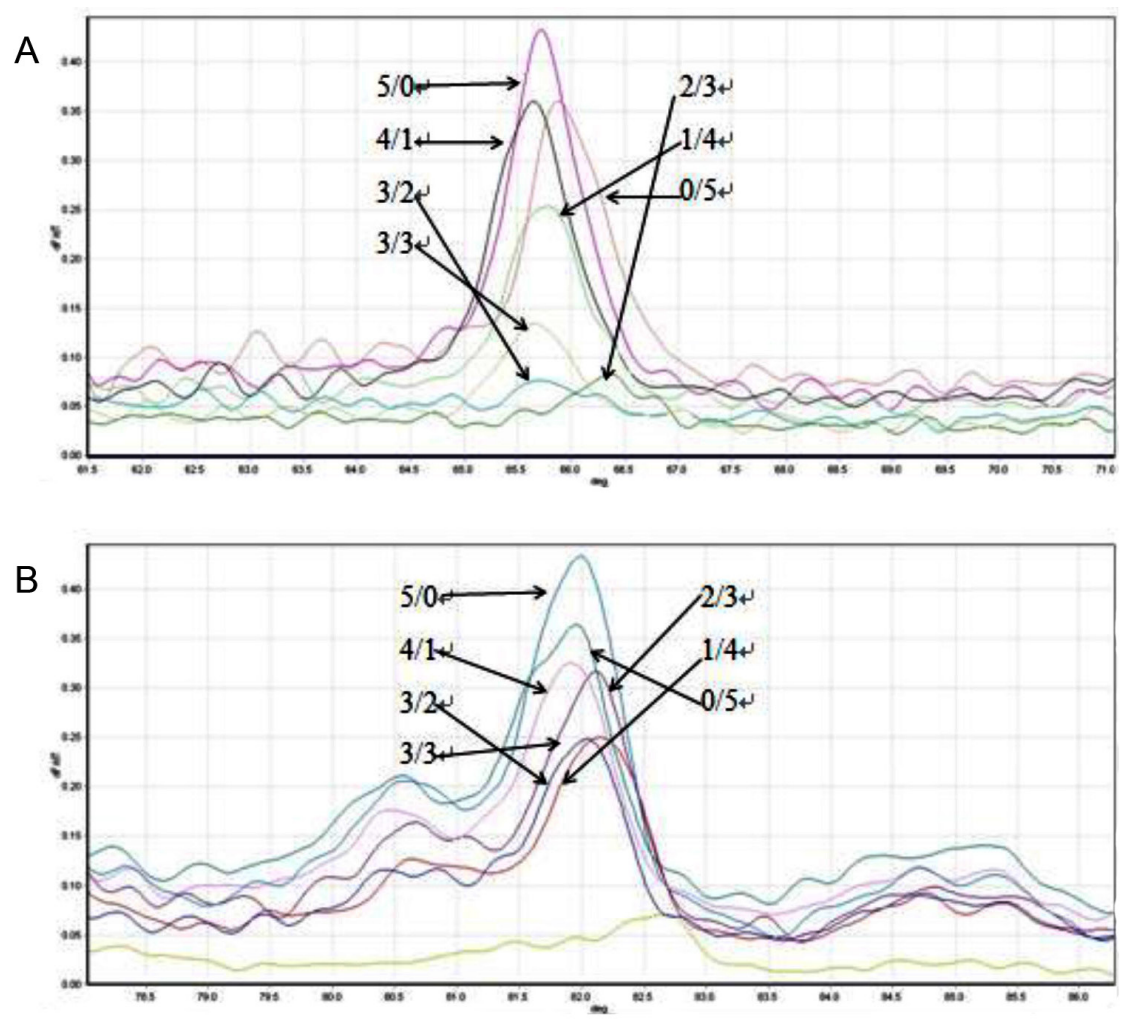

Figure 10. HRM assay of mixed samples, which produced different melting curves. A. Results of DYS447; B. results of DYS19.

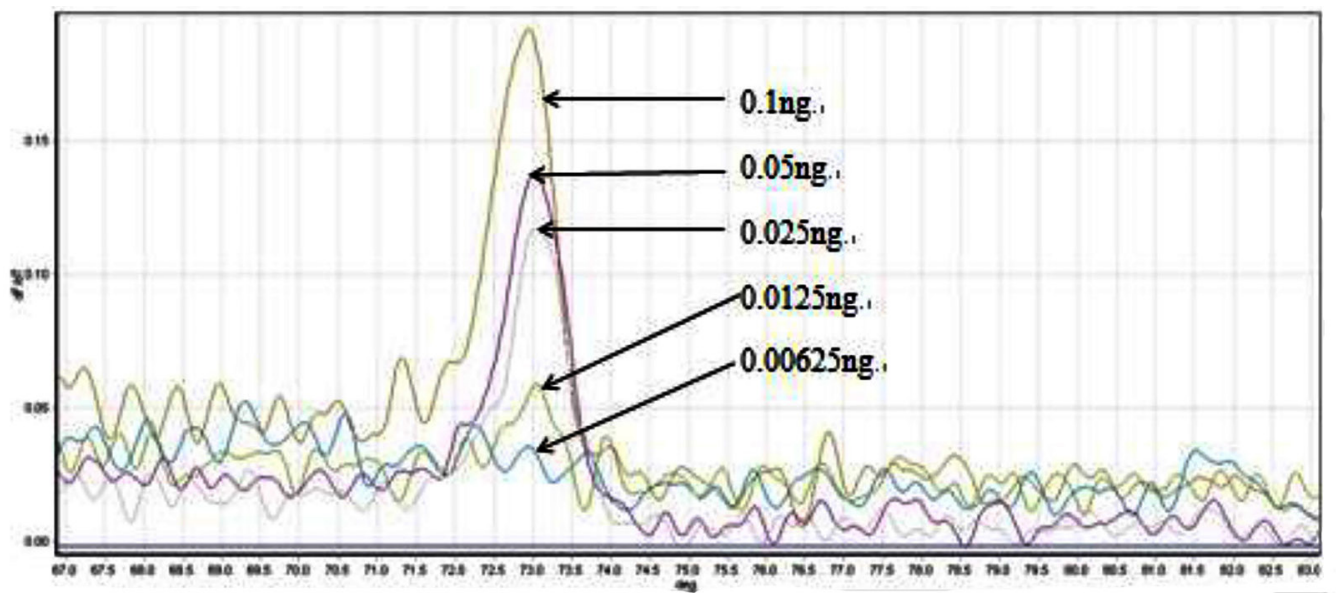

Figure 11. Sensitivity of the HRM assay for DYS393. The amounts of original DNA were $0.1,0.05,0.025,0.0125$, and $0.00625 \mathrm{ng}$ per reaction. 


\section{DISCUSSION}

Although DNA analysis technologies are widely used, CE-based genotyping on all biological evidence present at the scene of a crime remains laborious (Roewer, 2009; Thompson et al., 2012). In many cases, a large number of evidence materials are needed for quick screening. The key to whether these materials can play a critical role in analysis lies in whether technologies, particularly evidence-screening methods, can be performed efficiently (Pascali et al., 2012; Ziętkiewicz et al., 2012). Thus, high-performance technologies that can be used for screening are urgently needed. Because of its unique properties, DNA remains the best material for forensic application, and few commercial products for screening of forensic evidence for donor attribution using STRs or SNPs are available (Divne et al., 2005; Snyder et al., 2006). The general limitations of these assays are their relatively low power of discrimination, time-consuming, multi-tube operation, and lack the capacity to examine complex mixtures.

HRM analysis has been shown to be a relatively efficient, accurate, powerful, and inexpensive method for analyzing genetic variations and polymorphisms, particularly SNPs, using relatively low levels of genetic input (Nicklas et al., 2012; Nguyen et al., 2012). A subtle variation in DNA sequence leads to detectable changes in melting curve, and thus the allelic differences among PCR amplicons can be distinguished. This approach has been used to study genetic variability, for mapping, and for biodiversity analysis. Recently, HRM has been applied to analyze microsatellite markers. However, only 2 studies were identified in which this method was performed for forensic applications. Both of these studies confirmed that STR HRM analysis is a fast, simple and inexpensive genetic screening tool in forensic science (Nicklas et al., 2012; Nguyen et al., 2012), but no reports have described the use of Y-STR HRM analysis for forensic screening.

Unlike methods for genotyping STRs, a comparison-based method to screen materials for suspected bio-evidence must correctly assess whether the genotype of an unknown sample(s) differs from or is the same as that of the reference(s); genotyping of the unknown is not required, but genotypic distinctions between (or among) samples must be determined. The ability to discriminate between different samples should be the first consideration in the development of screening technologies (Nicklas et al., 2012; Distefano et al., 2012). In agreement with previous studies, we found that STRs analyzed by HRM revealed more genotypes than did CE (Nicklas et al., 2012; Nguyen et al., 2012), indicating that the HRM approach is a more powerful tool for discrimination. Using the proper STRs, HRM can be a very useful technique for distinguishing between genotypes. In our study, an assay consisting of 3 STRs showed sufficient power for useful screening; however, large population studies are required to support this claim.

Since evidentiary samples are often composed of more than one donor profile (i.e., mixtures), particularly in cases of sexual assault, Y-STRs are the most wildly used genetic markers; however, CE-based technologies are laborious, time-consuming, and expensive (Snyder et al., 2006; Ge et al., 2010; Nicklas et al., 2012; Distefano et al., 2012; Nguyen et al., 2012). In our study, use of the HRM assay for sample screening was simple and fast and showed low contamination. The sample Y-STRs could be discriminated within $2 \mathrm{~h}$ and all experiments could be performed in a single tube in a single step. As little as $0.025 \mathrm{ng}$ (equal to 2 cells) could be used, with the cost of each sample being less than US\$2, demonstrating that the HRM-based Y-STR assay is a powerful screening tool for forensic medicine. It is imperative that forensic scientists understand that melting patterns may change for these samples when the reaction system is changed, but this can be addressed by utilizing the normalization method described above. For mixtures, the complexity 
of melting patterns in single-source samples prohibits the identification of mixture components; however, the HRM assay remains useful. The sample and reference produce different curves, and thus mixed sample components can be identified in a convenient manner.

In conclusion, after the proper STR loci were selected (more than 3 loci), the strategies for HRM-based Y-STR screening in forensics would be as follows. For mixtures, HRM analysis can be used to sort the samples into groups, and then reduce the number of samples that should be examined for STRs can be accurate analyzed by CE. Evidentiary samples matching the victim's melting profile can be eliminated, whereas samples showing different melting patterns, indicating possible suspect(s) or mixtures, can be further analyzed by CE. For single-source samples, if an evidentiary sample is determined to originate from a single suspect, the sample is known to be a single-source sample. Thus, if there are several putative suspect samples or a single-source sample, it would be more efficient and cost-effective to screen the HRM patterns before performing STR analysis on each sample (Gale et al., 2008; Kuster and Von Elert, 2012).

Finally, we explored the use of the HRM assay in Y-STRs genotyping in forensic applications. Additional studies are needed prior to utilizing HRM in this field.

\section{Conflicts of interest}

The authors declare no conflict of interest.

\section{ACKNOWLEDGMENTS}

The authors would like to thank all of the volunteers who participated in this study. Research supported by the Natural Science Foundation of China (\#81260465) and the Scientific Research Cultivation Fund of Hainan Medical University (\#HY2012-012). Additionally, we would like to thank our colleagues at the Public Security Bureau of Haikou, particularly Xian-Wen Wang and Xiao-Min Fu, for their help during sample processing.

\section{REFERENCES}

Andersen MM, Eriksen PS, Mogensen HS and Morling N (2015). Identifying the most likely contributors to a Y-STR mixture using the discrete Laplace method. Forensic Sci. Int. Genet. 15: 76-83. http://dx.doi.org/10.1016/j.fsigen.2014.09.011

Butler JM (2007). Short tandem repeat typing technologies used in human identity testing. Biotechniques 43: Sii-v. http://dx.doi.org/10.2144/000112582

Butler JM, Buel E, Crivellente F and McCord BR (2004). Forensic DNA typing by capillary electrophoresis using the ABI Prism 310 and 3100 genetic analyzers for STR analysis. Electrophoresis 25: 1397-1412. http://dx.doi.org/10.1002/elps.200305822

Butler JM, Decker AE, Vallone PM and Kline MC (2006). Allele frequencies for 27 Y-STR loci with U.S. Caucasian, African American, and Hispanic samples. Forensic Sci. Int. 156: 250-260. http://dx.doi.org/10.1016/j.forsciint.2005.02.011

Distefano G, Caruso M, La Malfa S, Gentile A, et al. (2012). High resolution melting analysis is a more sensitive and effective alternative to gel-based platforms in analysis of SSR-an example in citrus. PLoS One 7: e44202. http://dx.doi.org/10.1371/journal.pone.0044202

Divne AM, Nilsson M, Calloway C, Reynolds R, et al. (2005). Forensic casework analysis using the HVI/HVII mtDNA linear array assay. J. Forensic Sci. 50: 548-554. http://dx.doi.org/10.1520/JFS2004505

Doutremepuich C (2012). Legal implication of DNA profiling. Bull. Acad. Natl. Med. 196: 1117-1129.

Er TK and Chang JG (2012). High-resolution melting: applications in genetic disorders. Clin. Chim. Acta 414: 197-201. http://dx.doi.org/10.1016/j.cca.2012.09.012

Gale N, French DJ, Howard RL, McDowell DG, et al. (2008). Rapid typing of STRs in the human genome by HyBeacon melting. Org. Biomol. Chem. 6: 4553-4559. http://dx.doi.org/10.1039/b813431f 
Ge J, Budowle B and Chakraborty R (2010). Interpreting Y chromosome STR haplotype mixture. Legal Med. 12: 137-143. http://dx.doi.org/10.1016/j.legalmed.2010.02.003

Jiao CG, Si HZ and Cui LH (2015). The evaluation for clinical prognostic factors of primary liver cancer treated by transcatheter arterial chemoembolization. Cancer Cell Res. 2: 179-184.

Keyser-Tracqui C and Ludes B (2003). Y-chromosome analysis. J. Soc. Biol. 197: 333-336.

Kuster CJ and Von Elert E (2012). High-resolution melting analysis: a genotyping tool for population studies on Daphnia. Mol. Ecol. Resour. 12: 1048-1057. http://dx.doi.org/10.1111/j.1755-0998.2012.03177.x

Liu T and Wu LQ (2015). To evaluate if the prognosis of curative resection in HCC patients is affected by alcholism. Cancer Cell Res. 2: 144-151.

Nguyen Q, McKinney J, Johnson DJ, Roberts KA, et al. (2012). STR Melting Curve Analysis as a Genetic Screening Tool for Crime Scene Samples. J. Forensic Sci. 57: 887-899. http://dx.doi.org/10.1111/j.1556-4029.2012.02106.x

Nicklas JA, Noreault-Conti T and Buel E (2012). Development of a fast, simple profiling method for sample screening using high resolution melting (HRM) of STRs. J. Forensic Sci. 57: 478-488. http://dx.doi.org/10.1111/j.1556-4029.2011.01981.x

Pascali JP, Bortolotti F and Tagliaro F (2012). Recent advances in the application of CE to forensic sciences, an update over years 2009-2011. Electrophoresis 33: 117-126. http://dx.doi.org/10.1002/elps.201100463

Roewer L (2009). Y chromosome STR typing in crime casework. Forensic Sci. Med. Pathol. 5: 77-84. http://dx.doi.org/10.1007/s12024-009-9089-5

Snyder K, Johnson K, Shick R, Sears J, et al. (2006). The potential of HUMACTBP2 (SE33) as a DNA screening locus. Internet J. Forensic. Sci. 2: 1-13.

Suehiro Y, Furuya T, Sasaki K and Hinota Y (2013). DNA polymorphisms. Rinsho Byori 61: 1001-1007.

Tang JP, Hou YP, Li YB, Wu J, et al. (2003). Characterization of eight Y-STR loci and haplotypes in a Chinese Han population. Int. J. Legal. Med. 117: 263-270. http://dx.doi.org/10.1007/s00414-003-0371-x

Thompson R, Zoppis S and McCord B (2012). An overview of DNA typing methods for human identification: past, present, and future. Methods. Mol. Biol. 830: 3-16. http://dx.doi.org/10.1007/978-1-61779-461-2 1

Vossen RH, Aten E, Roos A and den Dunnen JT (2009). High-resolution melting analysis (HRMA): more than just sequence variant screening. Hum. Mutat. 30: 860-866. http://dx.doi.org/10.1002/humu.21019

Walsh PS, Metzger DA and Higushi R (1991). Chelex 100 as a medium for simple extraction of DNA for PCR-based typing from forensic material. Biotechniques. 10: 506-513.

Wittwer CT (2009). High-resolution DNA melting analysis: advancements and limitations. Hum. Mutat. 30: 857-859. http://dx.doi.org/10.1002/humu.20951

Wojdacz TK (2012). Methylation-sensitive high-resolution melting in the context of legislative requirements for validation of analytical procedures for diagnostic applications. Expert Rev. Mol. Diagn. 12: 39-47. http://dx.doi.org/10.1586/erm.11.88

Ziętkiewicz E, Witt M, Daca P, Zebracka-Gala J, et al. (2012). Current genetic methodologies in the identification of disaster victims and in forensic analysis. J. Appl. Genet. 53: 41-60. http://dx.doi.org/10.1007/s13353-011-0068-7 